Edunomika - Vol. 03, No. 02 (Agustus 2019)

\title{
ANALISIS KINERJA KARYAWAN DI CV REGAR SPORT KABUPATEN WONOGIRI
}

\author{
Tribun Sitiambari ${ }^{1}$, Sri Hartono ${ }^{2}$, Sudarwati $^{3}$ \\ Fakultas Ekonomi Manajemen, UniversitasIslamBatikSurakarta \\ Email: songeunra96@gmail.com
}

\begin{abstract}
This study is intended to find the effect of work discipline, motivation and work environment on employee performance at CV REGAR SPORT, Wonogiri Regency. With the random sampling method the respondents used were 60 employees. With multiple linear regression analysis using IBM SPSS Statistics 23, the results of the study have a significant effect on work discipline, motivation and work environment on employee performance at CV REGAR SPORT, Wonogiri Regency. There is a significant effect of work discipline on employee performance at the Regar Sport CV and there is an influence but not significant motivation and work environment on employee performance at the Regar Sport CV.
\end{abstract}

Keywords: discipline, employee performance

\section{PENDAHULUAN}

Persaingan dunia usaha relatif semakin ketat, kinerja karyawan diharuskan untuk semakin meningkat. Untuk meningkatkan atau mempertahankan kinerja karyawan dengan cara evaluasi dan perbaikan sehingga meningkatkan kualitas dan kinerja

Peningkatan kinerja karyawan dapat dilakukan dengan cara mengkondisikan lingkungan kerja, meningkatkan disiplin kerja, serta memberikan motivasi kepada karyawan sehingga mereka langsung pada karyawan dalam melakukan pekerjaan maka menciptakan lingkungan kerja bersemangat dalam menjalankan tugas- tugasnya dengan baik.

Disiplin kerja yaitu sikap atau kondisi akan sadar pada diri karyawan terhadap tindakan mematuhi peraturan atau ketentuan yang berlaku di perusahaan.

Motivasi adalah suatu cara untuk memberikan arahan pada karyawan agar menjalankan tugasnya untuk mencapai target atau tujuan dengan bertanggung jawab.

Lingkungan kerja berpengaruh kondusif dapat me memberikan rasa puas dan mendorong semangat kerja karyawan. CV REGAR SPORT merupakan perusahaan penyedia sandang bagi masyarakat. Karena tingkat output produksi adalah cara untuk mengukur kinerja karyawan di CV Regar Sport, maka dapat dicari penyebab menurunnya hasil produksi dan kemudian ditemukan solusi untuk meningkatkan hasil produksi. 


\section{LANDASAN TEORI}

\section{Pengertian kinerja}

Kinerja karyawan yang baik atau bisa dikatakan berkualitas jika karyawan mampu menyelesaikan pekerjaannya sesuai dengan tugas yang diberikan dengan penuh tanggung jawab .

Menurut Fuad Mas'ud (2004) indikator pengukur kinerja karyawan ada lima yaitu:

1) Kuantitas

2) Kualitas

3) Efektivitas

4) Komitmen Kerja

5) Ketepatan Waktu

\section{Pengertian Disiplin}

Disiplin kerja merupakan seseorang yang sadar dalam menaati norma serta peraturan perusahaan, prestasi kerja karyawaan diperoleh apabila disiplin diterapkan dengan baik.

Menurut Soejono (dalam Jumjuma, 2011:11) indikator disiplin kerja karyawan yaitu sebagai berikut :

1) Tepat waktu

2) Bertanggung jawab

3) Menjaga dan merawat peralatan

4) Taat pada peraturan

5) Penggunaan kartu identitas dan pemakaian seragam

\section{Pengertian Motivasi}

Siagian (2009: 79), motivasi merupakan alasan utama seorang bekerja dalam perusahaan sebagai usaha memenuhi kebutuhannya baik secara sosial ekonomi dan kebutuhan lainnya. Indikator motivasi antara lain:

1) Antusias berprestasi tinggi

2) Kebutuhan akan perasaan diterima

3) Memiliki jabatan atau kedudukan yang baik

4) Kebutuhan akan perasaan ikut serta

\section{Hipotesis}

1) Diduga ada pengaruh positif dan signifikasi disiplin kerja, motivasi kerja dan lingkungan kerja pada kinerja karyawan di CV REGAR SPORT Wonogiri.

2) Diduga ada pengaruh yang positif disiplin kerja pada kinerja karyawan di CV REGAR SPORT Wonogiri.

3) Diduga ada pengaruh positif motivasi pada kinerja karyawan di CV REGAR SPORT Wonogiri.

4) Diduga ada pengaruh positif lingkungan kerja pada kinerja karyawan di CV REGAR SPORT Wonogiri. 


\section{METODE PENELITIAN}

Dengan metode diskriptif kuantitatif penelitian ini menggunakan pendekatan analisis regresi linier berganda. Responden 60 karyawan dengan metode random sampling yang dilakukan pada karyawan di CV Regar Sport dengan menyebar kuesioner.

\section{Analisis Regresi Linier Berganda}

Untuk membuktikan pengaruh variabel $\mathrm{X}$ terhadap variabel $\mathrm{Y}$ dengan cara analisis regresi linier berganda:

$$
\begin{aligned}
& \mathrm{Y}=\mathrm{a}+\mathrm{b}_{1} \mathrm{X}_{1}+\mathrm{b}_{2} \mathrm{X}_{2}+\mathrm{b}_{3} \mathrm{X}_{3}+\mathrm{e} \\
& \text { Keterangan : } \\
& \mathrm{Y}=\text { Kinerja Karyawan } \\
& \mathrm{a}=\text { Konstanta } \\
& \mathrm{b}_{\mathrm{n}}=\text { Koefisien regresi variabel bebas ke-n } \\
& \mathrm{X}_{1}=\text { Disiplin Kerja } \\
& \mathrm{X}_{2}=\text { Motivasi Kerja } \\
& \mathrm{X}_{3}=\text { Lingkungan Kerja e = Error }
\end{aligned}
$$

\section{HASIL DAN PEMBAHASAN}

\section{Analisis Regresi Linier Berganda}

\begin{tabular}{lcc}
\hline \multirow{2}{*}{ Model } & \multicolumn{2}{c}{ Unstandardized Coeficients } \\
& $B$ & Std. Error \\
\hline (Constant) & 7,166 & 2,881 \\
Disiplin & 0,35 & 0,111 \\
Motivasi & 0,081 & 0,177 \\
Lingkungan & 0,195 & 0,121 \\
\hline
\end{tabular}

Berdasarkan hasil uji dapat dirumuskan sebagai berikut : $\mathrm{Y}=7,166+0,350 \mathrm{X}_{1}+0,081 \mathrm{X}_{2}+0,195 \mathrm{X}_{3}+\mathrm{e}$

Dari hasil diatas dapat diinterprestasikan:

a. Nilai konstanta (a) =7,166 artinya apabila variabel disiplin, motivasi dan lingkungan nilainya adalah 0 (nol), maka variabel (Y) berada pada angka 7,166

b. Koefisien variabel disiplin kerja dari perhitungan regresi linier berganda nilai coefficients $=0,350$. Menunjukan jika disiplin kerja meningkat maka akan berpengaruh pada kinerja karyawan yang meningkat sebesar 0,350

c. Koefisien variabel motivasi dari perhitungan regresi linier berganda nilai coefficients= 0,081. Menunjukan jika motivasi kerja meningkat maka akan berpengaruh pada kinerja karyawan yang meningkat sebesar 0,081

d. Koefisien variabel lingkungan kerja dari perhitungan regresi linier berganda nilai coefficients $=0,195$. Menunjukan jika lingkungan kerja meningkat maka akan berpengaruh pada kinerja karyawan yang meningkat sebesar 0,195 


\section{Uji F}

Berdasarkan hasil uji nilai $F_{\text {hitung }}$ adalah sebesar 7,720, dikarenakan $F_{\text {hitung }}>\quad F_{\text {tabel }}$ $(7,720>2,77)$ dan signifikansi 0,000 < 0,05 maka Ho ditolak. Disimpulkan ada pengaruh yang signifikansi disiplin kerja, motivasi kerja dan lingkungan kerja pada kinerja karyawan.

\section{Uji t}

\begin{tabular}{lcc}
\hline \multicolumn{1}{c}{ Model } & $T$ & Sig. \\
\hline (Constant) & 2,487 & 0,016 \\
Disiplin & 3,146 & 0,003 \\
Motivasi & 0,455 & 0,651 \\
Lingkungan & 1,619 & 0,111 \\
\hline
\end{tabular}

Berdasarkan tabel diatas dapat disimpulkan:

1) Keputusan Nilai $t_{\text {tabel }}<t_{\text {hitung }}(2,003<3,146)$ maka Ho ditolak.

2) Keputusan Nilai $t_{\text {tabel }}>t_{\text {hitung }}(2,003>0,455)$ maka Ho diterima.

3) Keputusan Nilai $t_{\text {tabe }}>t_{\text {hitung }}(2,003>1,619)$ maka Ho diterima.

\section{KESIMPULAN}

Kesimpulan dari hasil dan pembahsan antara lain:

1) Ada pengaruh positif signifikasi disiplin kerja, motivasi dan lingkungan kerja pada kinerja karyawan di CV REGAR SPORT. Hal ini didasarkan pada hasil penelitian yaitu $t_{\text {hitung }}$ sebesar 7,720 dan signifikasinya $0,000<0,05$ maka Ho ditolak.

2) Ada pengaruh yang signifikan disiplin kerja pada kinerja karyawan di CV REGAR SPORT.

3) Ada pengaruh tetapi tidak signifikan motivasi kerja dan lingkungan kerja pada kinerja karyawan di CV REGAR SPORT..

\section{Saran}

Perusahaan lebih memperhatikan dan berusaha meningkatkan disiplin kerja, walaupun motivasi dan lingkungan kerja berpengaruhtidak signifikan tetapi secara simultan dengan disiplin kerja berpengaruh terhadap kinerja karyawan, oleh karena itu faktor motivasi dan lingkungan kerja harus tetap diperhatikan. 


\section{DAFTAR PUSTAKA}

Fauzi, U. (2014). Pengaruh Kompensasi Terhadap Kinerja Karyawan Pada PT.TRAKINDO UTAMA SAMARINDA. Ilmu Administrasi Bisnis 2(3), 172-185.

Sedamayanti. (2001). Sumber Daya Manusia dan Produktivitas Kerja, cetakan kedua. Bandung: Mandar Maju.

Sudarman, \& Suddin, A. (2010, Juni). Pengaruh Kepemimpinan, Motivasi, dan Lingkungan Kerja Terhadap Kinerja Pegawai Kecamatan Laweyan Kota Surakarta. Manajemen Sumberdaya Manusia Vol. 4 No. 1, 1-8. 